\title{
Analysis of consecutive droughts on the Canadian Prairies
}

\author{
A. C. Chipanshi* , K. M. Findlater, T. Hadwen, E. G. O'Brien \\ Agriculture and Agri-Food Canada, National Agroclimate Information Service, Regina, Saskatchewan, S4P 4L2, Canada
}

\begin{abstract}
Canadian Prairie precipitation totals were classified using fixed thresholds corresponding to the 10th percentile and median for the growing season (April to August) and agricultural year (September to August), in order to study the incidence of consecutive drought. These time frames are significant to water supply and agricultural activities. Consecutive drought events were classified as either back to back years with precipitation below the 10th percentile, or a year with precipitation below the 10th percentile followed by one or more years with less than median precipitation. The Palliser Triangle (an area in the southern Prairies) most consistently recorded consecutive drought events. While generally receiving higher precipitation totals, stations in the north were not immune to such events. Using the Palmer Drought Index, severe droughts were detected in the 1910s, 1930s and 1960s, corresponding to notably dry periods across the Canadian Prairies as a whole.
\end{abstract}

KEY WORDS: Canadian Prairies - Consecutive droughts · Agricultural year · Growing season · Dry spells Resale or republication not permitted without written consent of the publisher

\section{INTRODUCTION}

The Prairie region contains $>80 \%$ of Canada's cropland and rangeland, accounting for the majority of the country's agricultural activity (Statistics Canada 2002). Since domestic, industrial and irrigation activities depend on major river basins to provide for their water needs, the Prairies are a water deficit region, and particularly susceptible to drought. Given the uncertain nature of drought prediction, adaptation planning by crop and livestock farmers can best be aided by summarizing and analyzing historical characteristics such as duration, magnitude and frequency (Dracup et al. 1980, Bauer \& Welsh 1988). These characteristics are herein examined with relation to consecutive drought years, since such events can have serious impacts on agriculture. For crop farming, sustained yield losses resulting from consecutive years of drought will trigger consideration of alternative cropping options for the third year. For livestock farming, consecutive drought years will likely damage pasture grass beyond seasonal recovery, leading to feed shortages in the third year. Prolonged droughts also reduce the biodiversity of natural pasture (Tilman \& Haddi 1992), potentially affecting $80 \%$ of Prairie rangeland (Statistics Canada 2002). On-farm water supplies will be affected, since most farm ponds on the Canadian Prairies are designed to store water for only 2 years (AAFC 2002).

The Canadian Prairies lie in the rain shadow of the Rocky Mountains and are characterized by hot dry summers and long cold winters (Longley 1972, Lang \& Jones 1988, Wheaton 1998). Mean annual temperatures range from 1.5 to $3.5^{\circ} \mathrm{C}$, with mean winter temperatures of -12.5 to $-8.0^{\circ} \mathrm{C}$ and mean summer temperatures of 14.0 to $16.0^{\circ} \mathrm{C}$. During the summer season, maximum temperatures exceed $30^{\circ} \mathrm{C}$ on an average of 10 to $20 \mathrm{~d}$ in the southern Prairies (Phillips 1990). Precipitation totals are quite variable, with mean annual amounts ranging from $250 \mathrm{~mm}$ in the arid grasslands of southeast Alberta and southwest Saskatchewan to $700 \mathrm{~mm}$ in the Manitoba Plain, the warmest and most humid part of the region. Coupled with high wind speeds, such conditions do not lend themselves to a stable and adequate water supply. Surface and upper air circulation patterns during the summer months are often anomalous, resulting in little storm activity 
(Bonsal 1995), and the winter months are sometimes warmer than expected with very little snow accumulation (Shabbar \& Khandekar 1996). As a result, agricultural activities, especially crop and livestock farming, become vulnerable to drought if supplemental water supplies are not available.

Previous analyses of drought characteristics of the Canadian Prairies have included hydrological, climatological and agricultural perspectives. Hydrological studies, which have mostly concentrated on stream flow (Bauer \& Welsh 1988, Bell 1994, AES Drought Study Group 1986), give an indication of water availability for on-farm use and irrigation where applicable, but the bulk of hydrological studies have tended to provide outlooks and warnings for non-agricultural concerns such as hydro-power, flooding and recreation. Climatological studies examine drought as a deviation from a threshold such as the long term average, usually defined over a climatological base period of about $30 \mathrm{yr}$. Drought characteristics are then either summarized as a time series or analyzed spatially (Chakravarti 1976, Dey 1982, Jones 1984, Sauchyn \& Skinner 2001). For agricultural applications, the progressive nature of drought may make it misleading to use a single climatological threshold to define the start and end of a drought. However, a climatological depiction can provide a foundation for the definition of other types of drought. Agricultural drought studies attempt to link drought characteristics to specific agricultural impacts such as crop growth or yield (Ash et al. 1992, Wittrock \& Ripley 1999, Quiring \& Papakryiakou 2003). Some agricultural drought studies track plant water use, since it is closely related to dry matter production (Campbell et al. 1988, Raddatz et al. 1996). Nearly all agricultural drought studies are model-based, since it is quite difficult to measure water availability for specific agricultural uses. Limited availability of model inputs, both temporally and spatially, can present significant challenges to this approach. Given all of these difficulties, we drew some elements from both climatological and agricultural drought to define drought characteristics for this analysis.

In contrast previous studies, drought was defined using 2 timeframes as alternatives to the calendar year: the agricultural year and the growing season. The agricultural year (September to August) is suitable for explorations of drought impacts on perennial activities such as pasture growth, livestock production, reservoir storage and irrigation. The growing season (April to August) is appropriate for examinations of annual activities such as crop development and yield. Relative to past examinations of the Canadian Prairies, the denser station network in this study allowed for stronger spatial comparisons of water deficiency.

\section{METHODOLOGY}

The analysis was conducted using daily and monthly precipitation totals from 2 time periods: a $42 \mathrm{yr}$ period from 1959 through 2000, and a 92 yr period from 1909 through 2000. Since the agricultural year spans 2 calendar years, this scenario produced only 41 values for the shorter period and 91 for the longer period. The number of stations with complete data for each time frame was 100 and 8, respectively. The 1959-2000 timeframe provided a fairly dense network with which to perform spatial comparisons, while the 1909-2000 timeframe provided a detailed description of historical drought characteristics at specific locations. Since the intent was to perform a useful analysis for agricultural applications, the study was limited to stations within the agricultural landscapes of the Prairie provinces (Fig. 1). These landscapes are typically open grasslands with little topographic relief and a semi-arid to sub-humid climate. The station coverage provided a good representation of the major eco-zones. Daily and monthly precipitation totals were obtained from Environment Canada.

The percentile approach (Gibbs \& Maher 1967, Keyantash \& Dracup 2002) was used to define drought categories. At each station, annual precipitation totals for the agricultural year and growing season scenarios were ranked in ascending order and divided into percentile classes (Table 1). Each percentile class was then assigned a moisture description based on past validation studies of the study area (see www.agr.gc.ca/pfra/drought). The validation studies indicated that precipitation totals $<10$ th percentile coincided with the onset of drought, and this threshold was therefore chosen to define the beginning of a drought period in this analysis. Percentile thresholds are site specific and therefore the severity of each drought year was analyzed relative to historical conditions at that location, allowing for the spatial comparison of drought severity. The percentile approach has previously been used on the

Table 1. Percentile classes of precipitation, used on the Canadian Prairies to describe precipitation amounts for agricultural use

\begin{tabular}{|lc|}
\hline Percentile class & Description \\
\hline$<10$ & Extremely low \\
10 to 20 & Very low \\
20 to 40 & Low \\
40 to 60 & Mid range \\
60 to 80 & High \\
80 to 90 & Very high \\
90 to 100 & Extremely high \\
\hline
\end{tabular}


Canadian Prairies to analyze precipitation deficiency patterns (Chakravarti 1976), but with only 63 stations.

Consecutive drought events were defined using 2 criteria. Back to back years with precipitation $<10$ th percentile threshold were considered clear-cut consecutive drought events. Moreover, near-median precipitation in the year following a severe drought may be insufficient to fully alleviate adverse moisture conditions, especially for annual crops, as accumulated precipitation is temporarily stored in plant material and removed via harvesting. A second category of consecutive drought was therefore defined as consecutive years in which the first-year precipitation was $<10$ th percentile, while the second and subsequent years were below the median. Consecutive drought events were then counted at each station and com- pared with other sites using a series of maps, tables and graphs.

In order to provide a climatological context for dry phases, moisture deficits were compared to long term values by calculating precipitation anomalies. The anomaly for each year was calculated by subtracting the median value from the observed precipitation total, and expressed as a percentage of the median. Drought severity was assessed using the modified Palmer Drought Index (PDI) at stations with $92 \mathrm{yr}$ of data. The modified PDI (Akinremi et al. 1996) uses temperature, precipitation, and soil characteristics as inputs. The model couples the Versatile Soil Moisture Budget (VSMB) (Baier et al. 2000) to the original PDI (Palmer 1968). This coupling has improved the simulation of soil moisture on the Canadian Prairies, where sub-zero

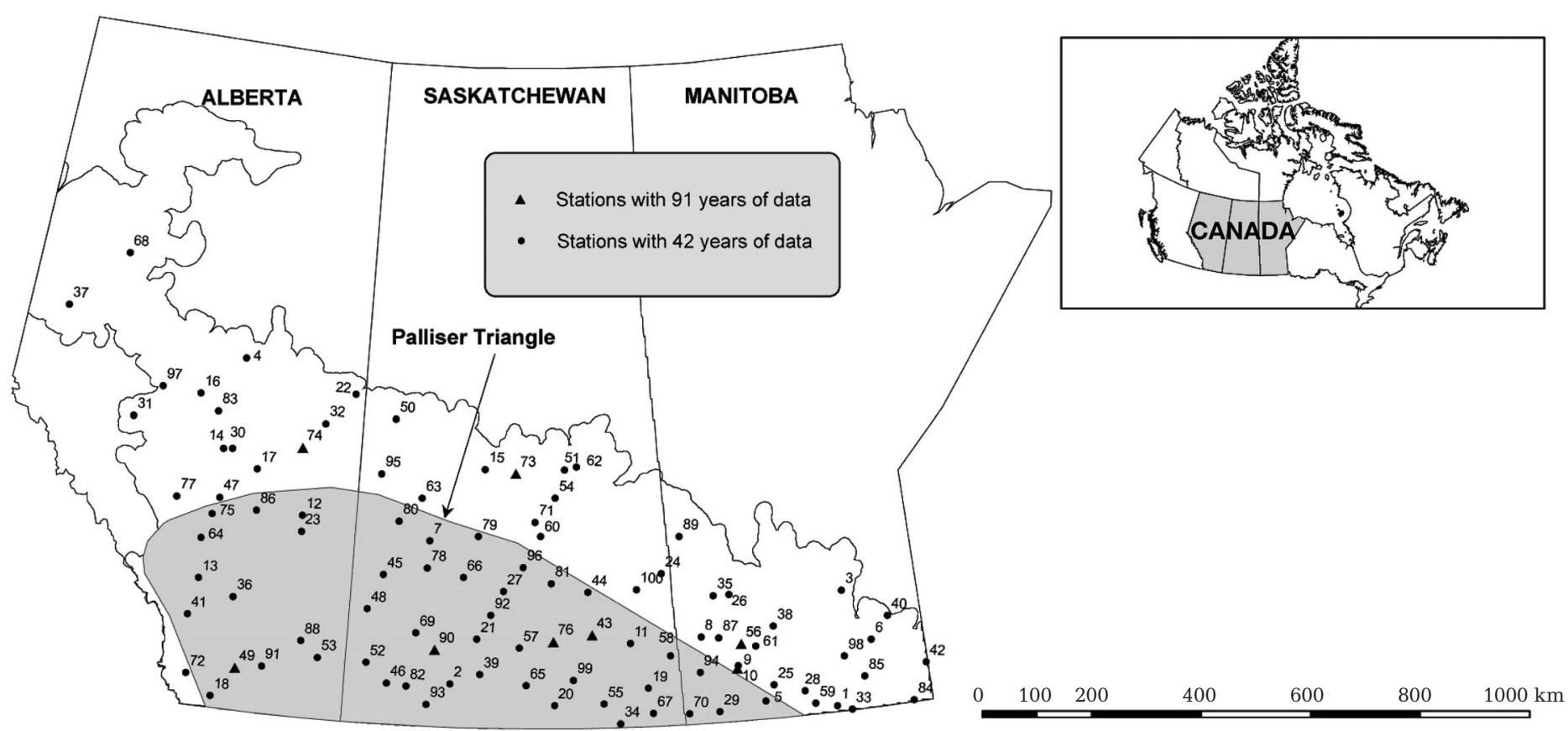

ID Name

1 ALTONA

2 ANEROID

3 ARBORG

4 ATHABASCA

5 BALDUR

6 BEAUSEJOUR

7 BIGGAR

8 BIRTLE

9 BRANDONNA

10 BRANDONCDA

11 BROADVIEW

12 BROWNFIELD

13 CALGARYA

14 CALMAR

15 CAMEO

16 CAMPSIE

17 CAMROSE

18 CARDSTON

19 CARLYLE
20 CEYLON

$\begin{array}{ll}21 & \text { CHAPLIN } \\ 22 & \text { COLDLAKEA } \\ 23 & \text { CORONATIONA } \\ 24 & \text { COTE } \\ 25 & \text { CYPRESSRIVER } \\ 26 & \text { DAUPHINA } \\ 27 & \text { DAVIDSON } \\ 28 & \text { DEERWOOD } \\ 29 & \text { DELORAINE } \\ 30 & \text { EDMONTONA } \\ 31 & \text { EDSONA } \\ 32 & \text { ELKPOINT } \\ 33 & \text { EMERSON } \\ 34 & \text { ESTEVANA } \\ 35 & \text { GILBERTPLAINS } \\ 36 & \text { GLEICHEN } \\ 37 & \text { GRANDEPRAIRIEA } \\ 38 & \text { GRASSRIVER } \\ 39 & \text { GRAVELBOURG } \\ 40 & \text { GREATFALLS }\end{array}$

41 HIGHRIVER

42 INDIANBAY

43 INDIANHEAD_CDA

44 KELLIHER

45 KINDERSLEYA

46 KLINTONEL

47 LACOMBECDA

48 LEADER2

49 LETHBRIDGECDA

50 LOONLAKE CDAEPF

51 LOSTRIVER

52 MAPLECREEK_NORTH

53 MEDICINEHATA

54 MELFORTCDA

55 MIDALE

56 MINNEDOSA

57 MOOSEJAWA

58 MOOSOMIN

59 MORDENCDA

60 MUENSTER

61 NEEPAWAWATER
62 NIPAWIN
63 NORTH_BATTLE-
FORDA
64 OLDS
65 ORMISTON
66 OUTLOOKPFRA
67 OXBOW
68 PEACERIVERA
69 PENNANT
70 PIERSON
71 PILGER
72 PINCHERCREEKA
73 PRINCEALBERTA
74 RANFURLY
75 REDDEERA
76 REGINAA
77
ROCKYMTN_HOUSEA
78 ROSETOWN

81 SEMANS

82 SHAUNAVON2

83 SION

84 SPRAGUE

85 STEINBACH

86 STETTLERNORTH

87 STRATHCLAIR

88 SUFFIELDA

89 SWANRIVER

90 SWIFTCURRENT CDA

91 TABER

92 TUGASKE

93 VALMARIE

94 VIRDEN

95 WASECA

96 WATROUS

97 WHITECOURTA

98 WINNIPEGA

99 YELLOWGRASS

100 YORKTONA

Fig. 1. Canadian Prairies: agricultural extent (area enclosed by continuous line) and locations of the precipitation stations. 
temperatures and snow are accounted for by using a new regional climate correction factor along with snow accumulation and melt relationships.

Since the growing season value of a moisture deficit does not reflect the distribution of precipitation events during the growth cycle, ranking it against historical drought events may not be sufficient to fully appreciate the impact of drought on annual crops. We analyzed the incidence of weeklong dry spells as an improved method of characterizing drought conditions within a single season. We defined a dry spell as a $7 \mathrm{~d}$ period without measurable precipitation, since crop processes may be disrupted when moisture supply is a limiting factor for an extended period. This definition assumes that moisture reserves are negligible prior to the dry spell. Our definition of a dry spell is similar to Brown \& Wyllie (1984), who defined dry spells as consecutive rainless days over a large area. A time series of the seasonal total number of days without precipitation was computed to investigate the change in dry spell frequency over time.

\section{PRECIPITATION ANOMALIES AND DROUGHT SEVERITY}

Precipitation totals below the long-term average result in meteorological drought when they persist over a large area for an extended period of time (Street \& Findlay 1981). Analysis of precipitation about its central tendency provides the context needed to explain other types of drought. Such an approach is less complex and easier to understand than hydrological or agricultural drought, and may therefore be more useful in decision-making. Two sample stations with long precipitation records were used to illustrate the application of a climatological threshold to examine precipitation departures (Fig. 2) for both the growing season and agricultural year. Higher median precipitation at Brandon in both scenarios indicates a wetter climate than that of Lethbridge. Dry phases were sometimes interrupted by a single wet year and vice versa, illustrating the variable nature of precipitation and perhaps the uncertainty in precipitation forcing mechanisms in the study area. Single wet years are unlikely to reverse longer-term dry conditions given the cumulative nature of water deficits.

Precipitation anomalies were analyzed in order to examine the frequency and length of wet and dry phases. A time series of precipitation anomalies was plotted for each of the 8 stations with $92 \mathrm{yr}$ of data. Anomalies were generally larger for the growing season scenario than the agricultural year scenario for both positive and negative values (Fig. 3). However, there were years when the growing season anomalies were smaller than those of the agricultural year scenario, such as 1929, 1954, 1963, 1984 and 1988 at Brandon, and 1988 and 1998 at Swift Current. Since the growing season on the Canadian Prairies is characterized by convective summer storms, the observed conditions during a particular season could swing between wet and dry, depending on the timing of storms. Based on the precipitation anomalies of the 8 stations, the following periods were generally dry during the growing season: 1914-1919, 1929-1931, 1936-1941，1945-1949，1957-1961，1967-1972, and 1983-1988. However, these periods were not uniformly dry at all locations, with exceptionally wet years observed at specific stations during dry phases. For example, during the drought year of 1961, while all other stations recorded deficits ranging from 22 to $71 \%$ of their median values, Ranfurly recorded a surplus of $12 \%$. This non-simultaneous occurrence of dry years is likely explained by the spatial variability of precipitation. The driest years in the growing season record were 1917 at Brandon, 1961 at Indian head, 1910 at Lethbridge and Prince Albert, 1917 at Minnedosa, 1941 at Ranfurly, 1937 at Swift Current, and 1967 at Regina (Fig. 3). With the exception of Indian Head, the driest growing season and agricultural year at each station did not occur within the same calendar year. This discrepancy is likely a result of differences in the timing of precipitation events between the 2 scenarios.

In order to examine the occurrence of widespread moisture deficits or surpluses across the study area, precipitation anomalies were summed for all 8 stations and plotted along with a 10 yr running mean (Fig. 4). The analysis was limited to the agricultural year scenario since it includes both winter and summer storms. The summed anomaly was marked by significant year-to-year variability, with the greatest interannual change recorded between 1960 and 1961. The difference in the anomalies of those years was $49 \%$ of the median value, swinging from very wet in 1960 to very dry in 1961. The drop from 1916 to 1917 was only slightly smaller at $47 \%$, while the 2 year drop from 1927 to 1929 far surpassed any single year variation at $71 \%$ of the median value. The $10 \mathrm{yr}$ running mean showed a period of relatively low variability from the mid 1960s to the mid 1990s that may require further study. On average, the driest $10 \mathrm{yr}$ periods in the $92 \mathrm{yr}$ record were 1929-1938 and 1958-1967, while the wettest periods were 1947-1956 and 1990-1999.

The PDI (Fig. 5) was used to illustrate drought severity at stations with 92 yrof climate data. The PDI is an indication of moisture availability and therefore has implications for agricultural impacts such as crop yield. The time series of the PDI was quite similar to 

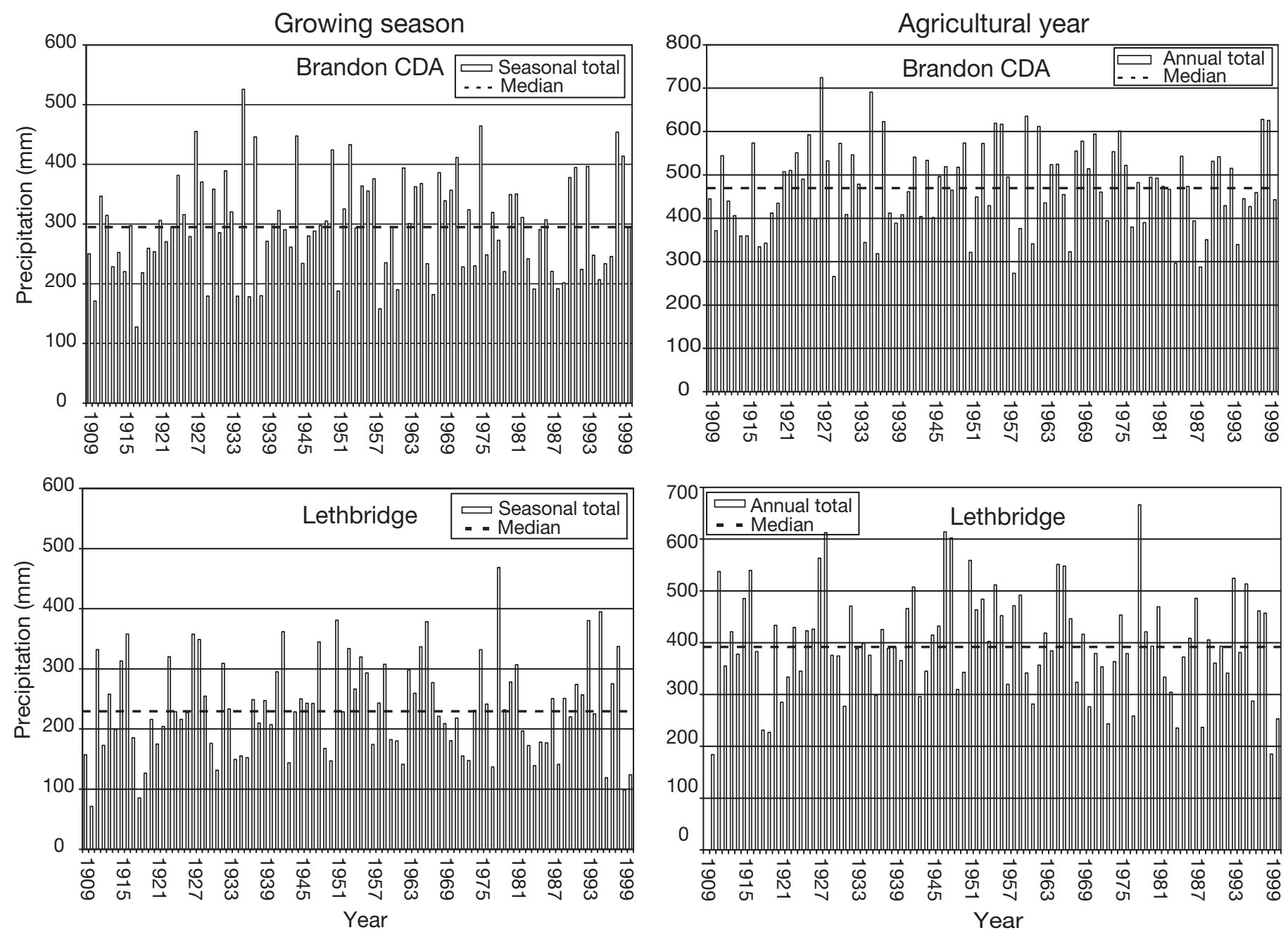

Fig. 2. Growing season and agricultural year precipitation totals illustrating the variability of precipitation about the median. Note different $y$-axis scales

the general pattern of moisture anomalies (Fig. 4), but the PDI provided more detail on the severity of moisture deficiency or surplus in each year. Based on the drought category thresholds used in the North American Drought Monitor (NADM), all 8 stations experienced moderate $(\mathrm{PDI}=-2)$ or extreme drought $(\mathrm{PDI}=$ -4) at some time (Svoboda et al. 2002). Extreme drought was recorded at Indian Head in 1931 and 1961 and at Minnedosa in 1929 (Fig. 5A), at Lethbridge in 1910 and 2000 and at Regina in 1915 and 1937 (Fig. 5B). Of the 4 stations, the most severe drought was recorded at Indian Head in 1961. For the NADM, these PDI thresholds were linked to impacts based on conditions in the United States, and are now being investigated in Canada. Moderate droughts are indicative of some damage to crops and pastures, while extreme droughts indicate major crop and pasture losses.

\section{SPATIAL CHARACTERISTICS OF CONSECUTIVE DROUGHTS}

In order to assess the spatial attributes of consecutive droughts, the station network was expanded to include all stations with $42 \mathrm{yr}$ of data. Instances where consecutive growing season years fell below the 10th percentile were counted and their frequency was plotted on a map. This showed that the majority of stations had no record of clear-cut consecutive droughts, although significant areas of southern Saskatchewan and Manitoba recorded at least one such event.

The threshold approach to consecutive drought analysis assumes that the drought ends when precipitation surpasses a fixed threshold. Some ecosystem types, such as pasture, commonly take more than one season of above average precipitation to recover from serious drought (Tilman \& Haddi 1992). Therefore, for 

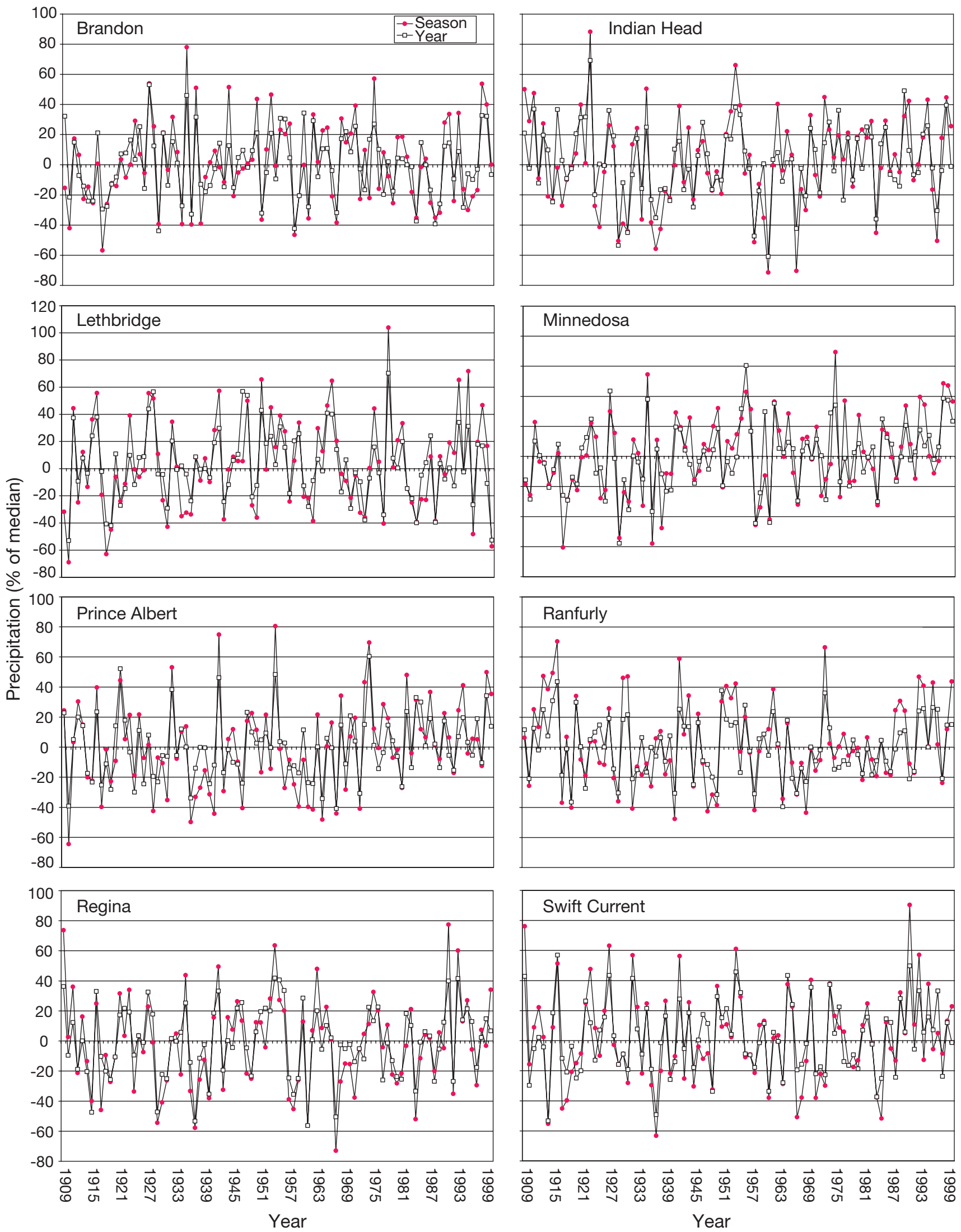

Fig. 3. Precipitation anomalies for the agricultural year and growing season scenarios, expressed as a percentage of the median 


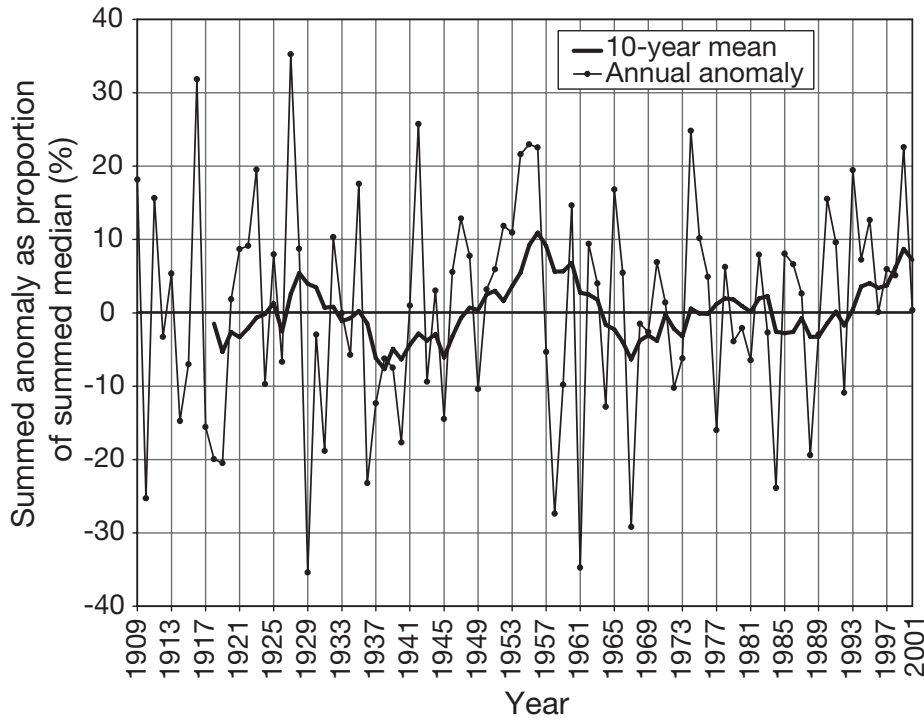

Fig. 4. Summed anomalies for all stations during the agricultural year, with a $10 \mathrm{yr}$ running mean

certain agricultural applications, median precipitation amounts in the second year are considered non-recovery years and an extension of drought conditions. The frequency of consecutive growing season droughts in the Prairie provinces increased significantly when considering instances where the first drought year precipitation fell below the 10th percentile while the second and subsequent years fell below the median (Fig. 6). Swift Current and Klintonel in southwestern Saskatchewan topped the list with 4 such consecutive droughts each, highlighting the fact that the highest concentration was found in southern and southwestern Saskatchewan. The pattern in Alberta was less clear, with Cold Lake in the northeast recording 4 instances, while 6 stations distributed across the province each recorded 3 instances. In Manitoba, the highest frequency was found in the northwest, with 3 stations each recording 3 instances. Southern areas of the Prairie provinces generally experienced at least one such consecutive drought, broadly coinciding with the drier portion of the Northern Great Plains known as the Palliser Triangle (Nemanishen 1998).

Instances of consecutive agricultural years falling below the 10th percentile were analyzed in the same manner as for the growing season. Most locations recorded either 0 or 1 instance of such consecutive drought. As with the growing season, the frequency of consecutive agricultural year droughts increased significantly when taking into account non-recovery years (Fig. 6). The station recording the highest frequency was Cold Lake in northeastern Alberta with 5 instances, followed by Edmonton with 4. Eight other Alberta stations recorded 3, with 4 in the north and 4 in the south. Seven stations in southeastern Sas- katchewan and 1 station in southwestern Manitoba represented the most extensive area of high frequency with 3 instances each. In Manitoba, Arborg in the north recorded 4 instances, while the south-central region had fairly high counts with Altona at 4, and Winnipeg and Deerwood at 3 each.

When the growing season and agricultural year counts of consecutive droughts were compared, the centres of highest frequency did not match between the 2 scenarios. Southwestern Saskatchewan had the highest frequency of consecutive growing season droughts, while southeastern Saskatchewan had the highest frequency in the agricultural year scenario. This mismatch may be attributed to differences in the timing of precipitation events between the 2 scenarios.

\section{HISTORICAL PERSPECTIVES OF DROUGHT SEVERITY}

In describing the worst droughts that have occurred on the Canadian Prairies in recent years, stations with $42 \mathrm{yr}$ of data were used in order to provide good coverage of the study area. Individual drought years were identified at each station as years with accumulated precipitation $<10$ th percentile. The number of stations registering such a drought was counted for each year in order to examine the extent and severity of historical droughts. Years with a high number of stations reporting drought were considered more severe than those with fewer stations. For both the growing season and agricultural year scenarios, 1961 was ranked as the driest year by the greatest number of stations (Table 2), with 29 stations recording it as such for the growing season and 42 for the agricultural year. For both scenarios, the 1960s contained the 2 driest years as well as the 7 th driest. The 1980 s contained 3 of the 8 driest years for the growing season, while containing 4 for the agricultural year. The 1970 s contained 2 of the driest 8 years for the growing season and 1 for the agricultural year, while the 1990s registered no years among the driest 8. By this measure 1961 and 1967 were far drier than any other years, and because mitigation and adaptation programs were less developed in the 1960s than at present, impacts were probably worse than might be expected from a present day drought of the same severity.

\section{NATURE OF DRY SPELLS ON THE CANADIAN PRAIRIES}

Dry spells may be defined differently depending on the purpose of the study. For example, Bonsal et al. (1993 p. 867) defined dry spells as '10 consecutive days 

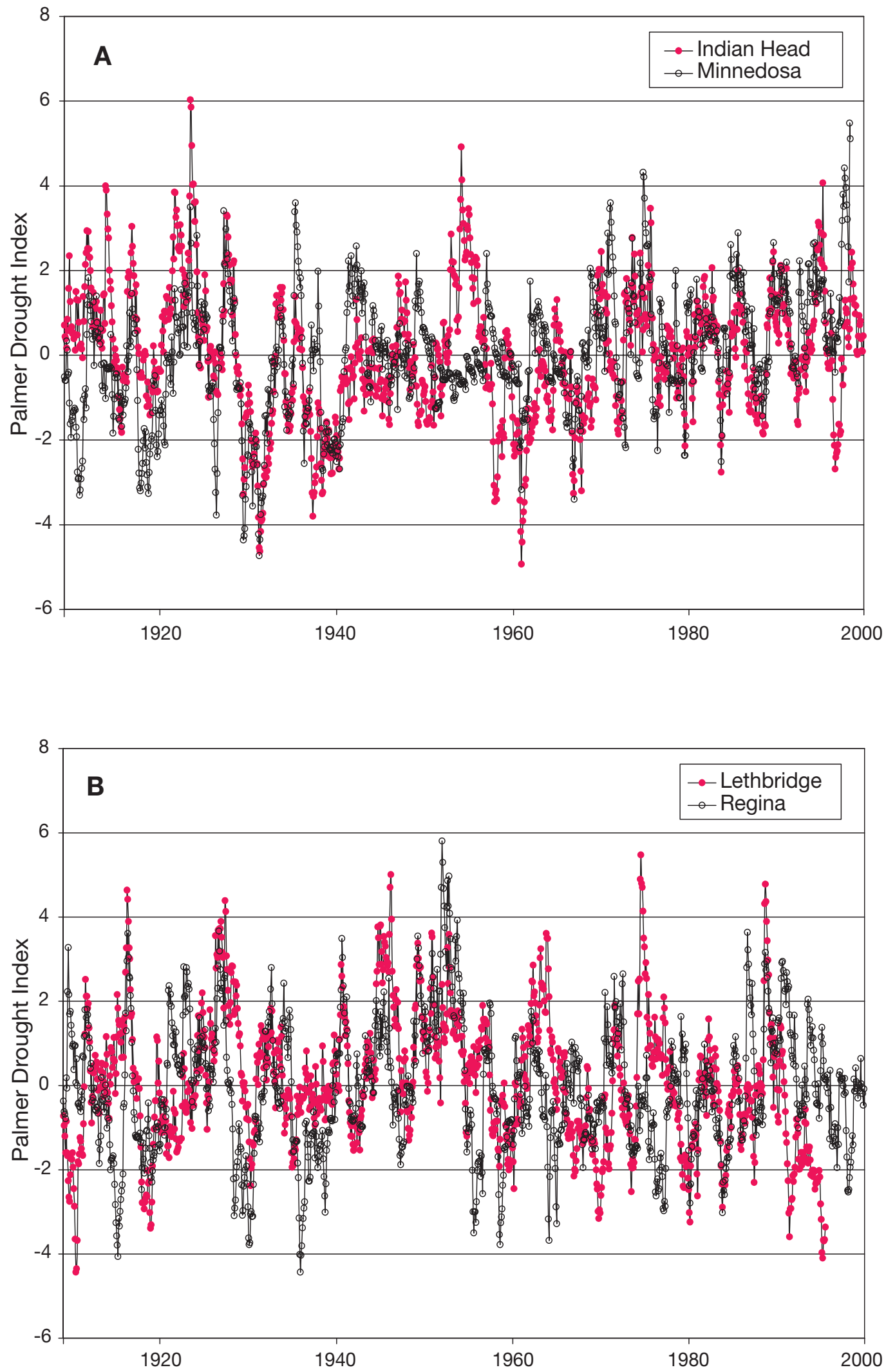

Fig. 5. Monthly Palmer Drought Indices (1909-2000) calculated from the Canadian version of the modified Palmer Drought Model. (A) Indian Head and Minnedosa; (B) Lethbridge and Regina 


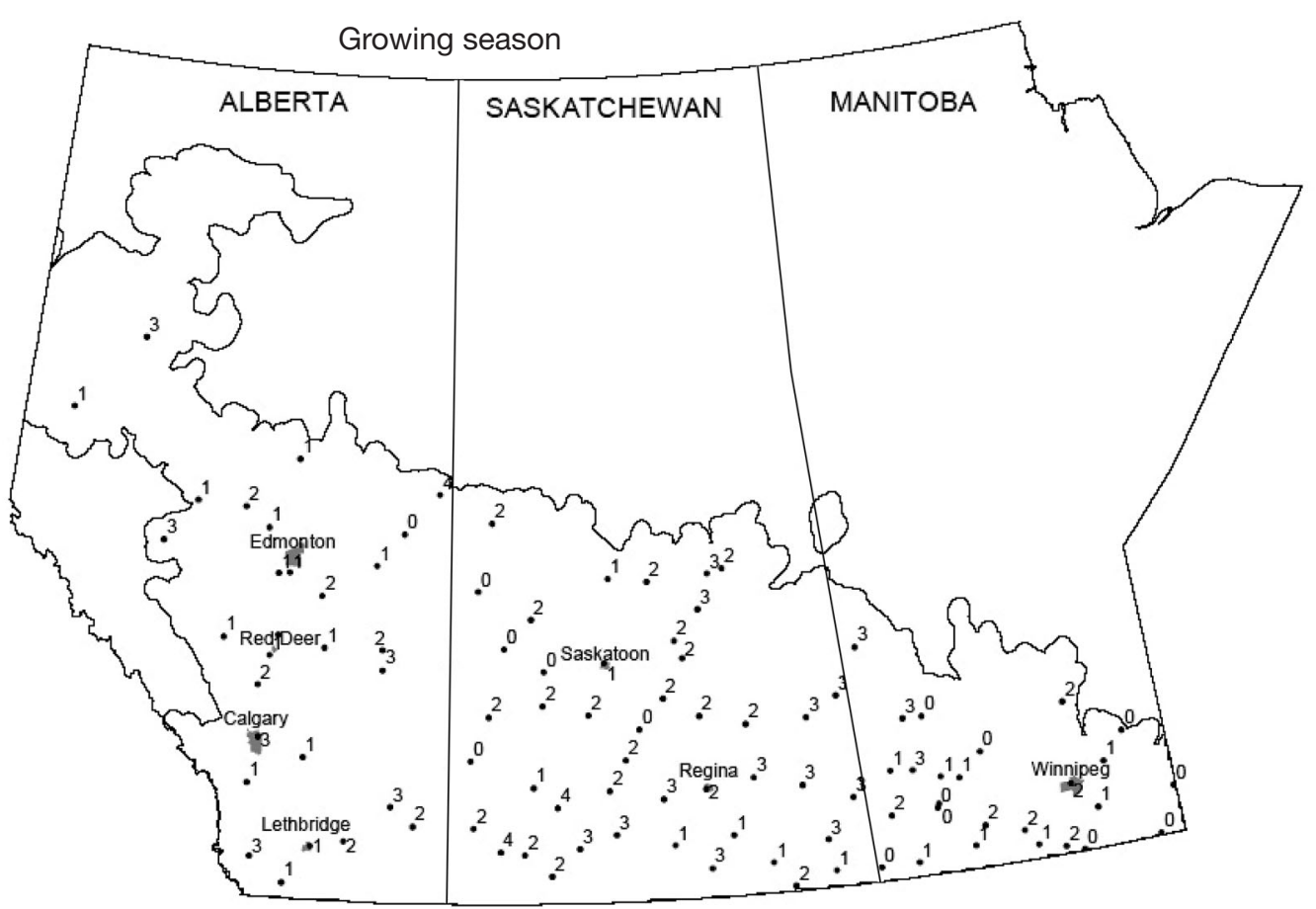

Fig. 6. Count of consecutive droughts for which the first year fell below the 10th percentile while subsequent years received median precipitation or less during the growing season, April to August (top), and during the agricultural year, September to August (bottom) (1959-2000)

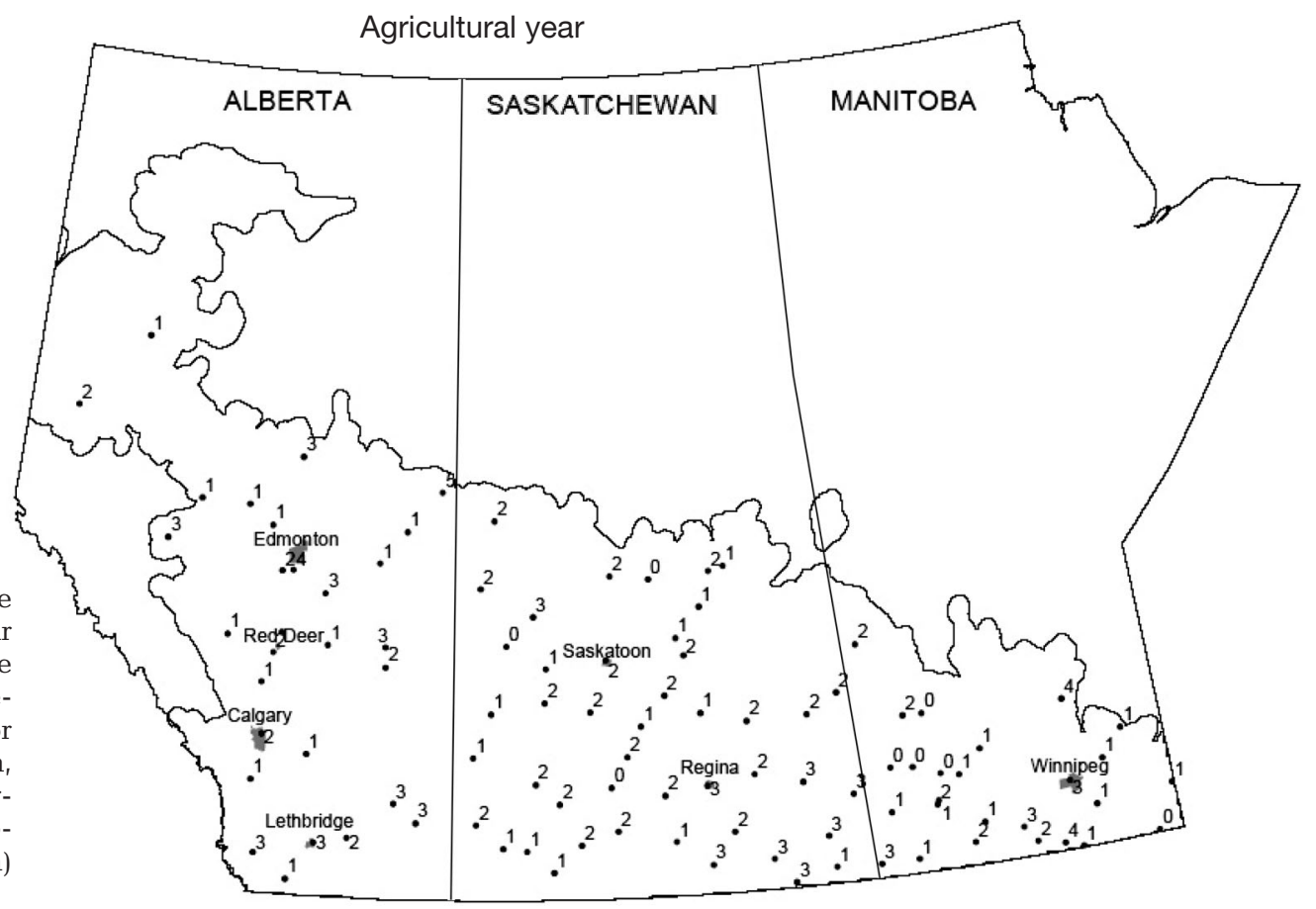

during which $50 \%$ or more of the stations within the study area received no measurable precipitation and the entire period has above average $500 \mathrm{hPa}$ height anomalies'. Bonsal's definition was intended to combine the spatial implications of drought with the meteorological forcing, since positive heights indicate a lack of uplift and absence of cloud formation. In the study at hand, a dry spell was defined as a minimum of $7 \mathrm{~d}$ without measurable precipitation at an individual station during the growing season. This definition was intended to account for most rainless events that would negatively impact crop growth and development. The $7 \mathrm{~d}$ dry spells were counted over the course of the growing season and compared between locations. 
Table 2. Rank of number of stations reporting severe drought (defined as precipitation totals below the 10th percentile)

\begin{tabular}{|lccccccccccc|}
\hline Year & 1 & 2 & 3 & 4 & 5 & 6 & 7 & 8 & 9 & 10 & Total \\
\hline \multicolumn{7}{|l}{ Growing season } \\
1961 & 29 & 19 & 13 & 7 & 4 & 3 & 2 & 1 & 2 & 0 & 80 \\
1967 & 24 & 16 & 13 & 10 & 7 & 2 & 0 & 1 & 0 & 1 & 74 \\
1984 & 2 & 5 & 6 & 10 & 6 & 2 & 3 & 1 & 1 & 0 & 36 \\
1988 & 6 & 5 & 6 & 3 & 2 & 1 & 2 & 1 & 1 & 0 & 27 \\
1972 & 1 & 2 & 4 & 5 & 3 & 3 & 1 & 1 & 0 & 0 & 20 \\
1979 & 4 & 1 & 1 & 4 & 1 & 3 & 2 & 1 & 0 & 0 & 17 \\
1969 & 0 & 2 & 5 & 4 & 3 & 1 & 1 & 0 & 0 & 0 & 16 \\
1980 & 3 & 3 & 1 & 3 & 2 & 1 & 0 & 1 & 0 & 0 & 14 \\
Agricultural year & & & & & & & & \\
1961 & 42 & 15 & 14 & 7 & 1 & 4 & 0 & 0 & 0 & 0 & 83 \\
1967 & 9 & 10 & 12 & 16 & 10 & 6 & 0 & 1 & 0 & 1 & 65 \\
1988 & 11 & 9 & 12 & 9 & 4 & 4 & 2 & 0 & 1 & 0 & 52 \\
1984 & 1 & 6 & 4 & 11 & 2 & 9 & 4 & 1 & 0 & 0 & 38 \\
1977 & 0 & 0 & 9 & 5 & 4 & 6 & 4 & 1 & 0 & 0 & 29 \\
1980 & 2 & 4 & 3 & 1 & 1 & 1 & 1 & 0 & 1 & 0 & 14 \\
1969 & 1 & 0 & 3 & 3 & 0 & 2 & 2 & 0 & 0 & 1 & 12 \\
1981 & 0 & 1 & 2 & 3 & 3 & 0 & 1 & 1 & 0 & 0 & 11 \\
\hline
\end{tabular}

Stations with 92 yr of data generally showed a reduction over time in the frequency of growing season dry spells (Fig. 7), while exhibiting marked year-to-year variability. For the 100 stations with $42 \mathrm{yr}$ of data, the number of dry spells by year was plotted as a time series to which a regression line was fitted. Only 13 had positive slopes, with the majority in Manitoba, mostly between Lakes Manitoba and Winnipeg. It was unclear why this area showed this bias. The remainder of stations in the study area had negative slopes, indicating a general decrease in the severity of growing season drought events. However, when the slopes were tested for significance at the $5 \%$ level, the trend did not register as statistically significant. The general reduction in the number of dry spells on the Canadian Prairies requires further study to determine how these may be related to other findings that suggest that precipitation totals have increased by about 5 to $10 \%$ since the 1950s (Mekis \& Hogg 1999).

\section{DISCUSSION AND CONCLUSIONS}

The analysis considered differences between the agricultural year and growing season scenarios in examining drought frequency on the Canadian Prairies, with relevance to perennial and annual agricultural cycles, respectively. Consecutive drought events were used to assess the risk of extended drought in order to provide a simple framework to examine the vulnerability of the Prairie agricultural landscape to drought during the 20th century. The frequency of consecutive drought did not appear high, but increased when the definition of drought was expanded to include years in which recovery was unlikely. A non-recovery year was defined as a year with below median precipitation following a drought year. As defined by rainless days, dry spells may have decreased over the past 40 years, but drought continues to be a characteristic feature of the Prairie landscape. Because of the irregular and unpredictable nature of drought, most water sensitive activities are vulnerable. Vulnerability needs to be planned for, because most climate change projections for the Canadian Prairies suggest some degradation of agricultural land as a result of increasing evapotranspiration rates in a warmer climate (Cutforth et al. 1999, Nyirfa \& Harron 2001, Shepherd \& McGinn 2003). These conditions may increase the incidence of both dry spells and prolonged multi-year droughts. Although climate change scenario predictions are uncertain, proxy analyses of historical drought events suggest that the Canadian Prairies have experienced droughts of even greater severity and length during the past few centuries than those of the 20th century, increasing the likelihood of more devastating droughts in the future (Sauchyn \& Skinner 2001).

Contrary to what has previously been reported in the literature, consecutive droughts are not exclusive to the southern Prairies. Such events were recorded at northern locations such as Grande Prairie and Cold Lake in Alberta and may be linked to changing climatic patterns. Although data scarcity may be limiting, further investigation is needed and climate change scenario studies might provide some answers.

The dry spell analysis provided a measure of the impact on crop growth and development. A $7 \mathrm{~d}$ period without precipitation is likely to trigger observable changes in plant growth and development if there are no existing moisture reserves. This period also matches the reporting timeframes of Prairie provincial crop conditions and the assessment of growth vigour from the Normalized Difference Vegetative Index (NDVI). These results may therefore be directly applied to impact studies such as crop condition assessments. However, for most cropping practices the timing of dry spells has a greater impact than their frequency. Further exploration is needed to produce a framework for the temporal analysis of dry spells during crop development stages. This will help define the onset and cessation of drought with respect to crop or pasture growth, which is currently done using drought indices such as the PDI or Standardized Precipitation Index. These indices often misinterpret the beginning and end of droughts, since the relationship between moisture deficiency and crop functions is complex. The change in the moisture regime over time could further 

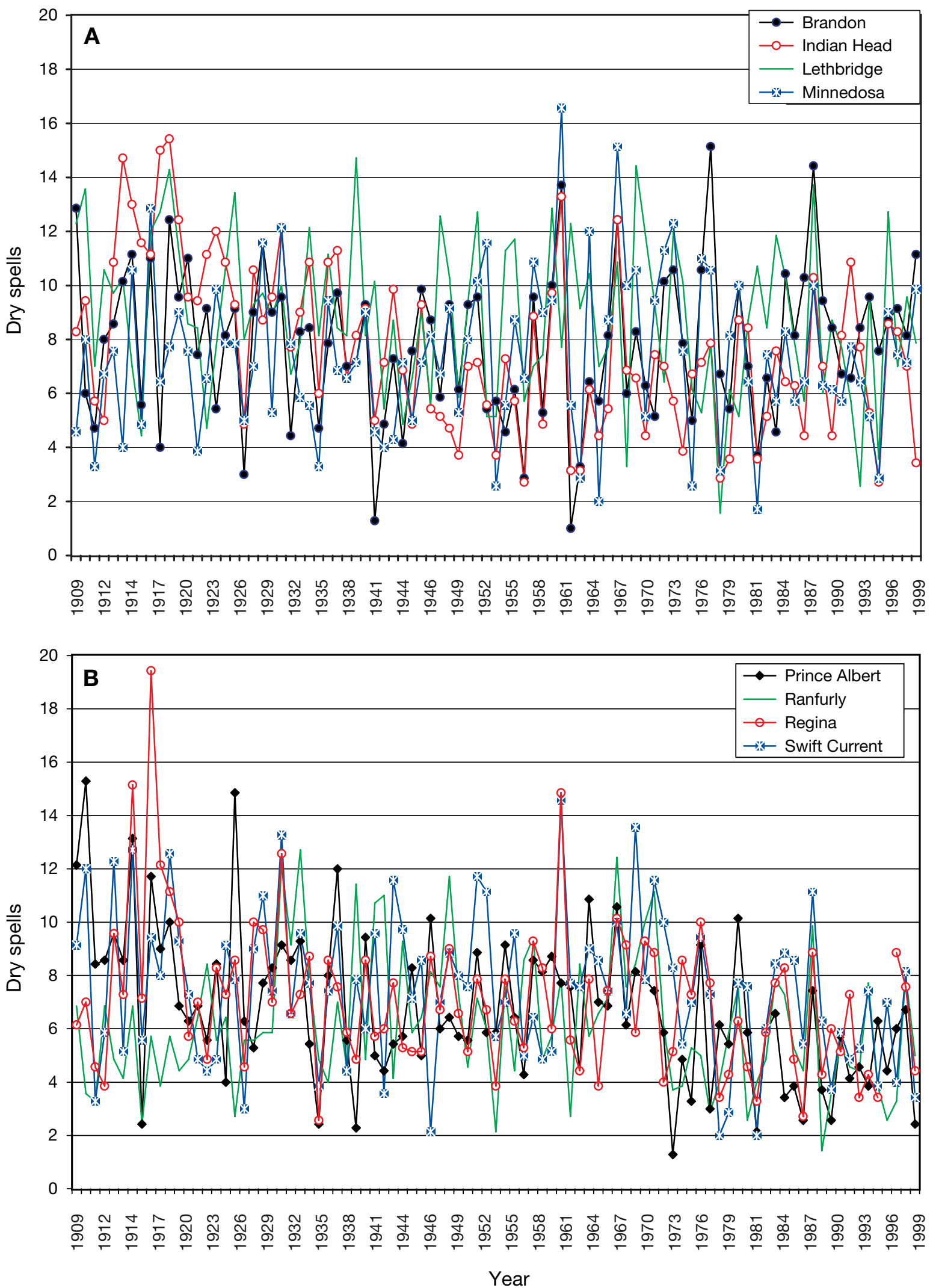

Fig. 7. Annual count of growing season dry spells at 8 locations. (A) Brandon, Indian Head, Lethbridge and Minnedosa; (B) Prince Albert, Ranfurly, Regina and Swift Current 
be examined using more elaborate techniques such as decadal mean severity statistics (Quiring 2004).

The analysis of drought conducted here assumed a large, consistent, and independent sample of precipitation data drawn from a single station population. In response to data paucity problems we used 2 timeframes to perform the analysis. Although limited to 8 stations, the 92 yr data set provided the long record required to explore historical drought characteristics at individual locations, allowing for the analysis of drought occurrence and severity. On average, the driest $10 \mathrm{yr}$ periods for the agricultural year were 1929-1938 and 1958-1967, although both periods were interrupted by surplus years, and dry years were not necessarily dry at all locations. The interruption of a dry phase by wet years complicates the view that drought on the Prairies can be described in terms of definite cycles alone. For example, it is unclear why a single wet year such as 1916 at the 8 locations studied would be surrounded by very dry years. Examination of drought severity using the PDI showed instances of exceptional drought at each station. While the frequency of exceptional drought is low, it is quite important and is certain to recur. Drought severity must next be explored by examining the impact of drought on water sensitive activities. This might be accomplished by relating drought to yield data for crops and pastures, or appropriate water resource data such as flow volumes.

The incidence of consecutive drought confirms the widespread nature of drought on the Canadian Prairies and shows that northern areas are not immune, as has generally been thought. As defined using the PDI, severe droughts were recorded in the $1910 \mathrm{~s}$, the $1930 \mathrm{~s}$ and the $1960 \mathrm{~s}$, corresponding to notably dry periods across the Canadian Prairies. Although the statistical significance of the decline in the number of dry spells is in question, this trend requires further study, as does the timing of dry spells with respect to agricultural activities.

Acknowledgements: We are grateful to Environment Canada for supplying precipitation data, and to the Computer Service Division of AAFC-PFRA for assisting with data preparation. In particular, special thanks go to D. Braithwaite for writing all data-summarizing routines. Dr. B. Bonsal's helpful comments on the manuscript are also gratefully appreciated.

\section{LITERATURE CITED}

AES Drought Study Group (1986) An applied climatology of drought in the prairie provinces, Report \# 86-4. Canada Climate Centre, Atmospheric Environment Service, Downsview

AAFC (2002) Quality farm dugouts. Agriculture and AgriFood Canada, Regina
Akinremi OO, McGinn SM, Barr AG (1996) Evaluation of the Palmer Drought Index on the Canadian Prairies. J Clim 9:897-905

Ash GHB, Shaykewich C, Raddatz RL (1992) Moisture risk assessment for spring wheat on the eastern Prairies: a water use simulation model. Climatol Bull 26:65-78

Baier WJ, Boisvert B, Dyer JA (2000) The Versatile Soil Moisture Budget (VSMB) reference manual. ECORC Contribution No. 001553, Agriculture and Agri-Food Canada, Eastern Cereal and Oilseed Research Centre, Ottawa

Bauer DJ, Welsh LE (1988) Frequency analysis of meteorological drought in the Saskatchewan portion of the South Saskatchewan River Basin. Report \#C4, Hydrometeorological Research Division, Canadian Climate Centre

Bell BJ (1994) Annual unit runoff on the Canadian Prairies. Hydrology Report \#135, Prarie Farm Rehabilitation Administration (PFRA), Regina

Bonsal BR, Chakravarti AK, Lawford RG (1993) Teleconnections between North Pacific SST anomalies and growing season extended dry spells on the Canadian Prairies. Int J Climatol 13:865-878

Bonsal BR (1995) Teleconnections between ENSO events and growing season precipitation on the Canadian prairies. Phd Dissertation, University of Saskatchewan, Saskatoon

Brown DM, Wyllie WD (1984) Growing season dry spells in southern Ontario. Climatol Bull 18:15-30

Campbell CA, Zenter RP, Johnson PJ (1988) Effects of crop rotation and fertilization on the quantitative relationship between spring wheat yield and moisture use in southern Saskatchewan. Can J Soil Sci 68:1-16

Chakravarti AK (1976) Precipitation deficiency patterns in the Canadian prairies, 1921 to 1970 . J Can Plains Res Cent 1:95-110

Cutforth HW, McConkey BG, Woodvine RJ, Smith DG, Jefferson PG, Akinremi OO (1999) Climate change in the semiarid prairie of southwestern Saskatchewan: late winterearly spring. Can J Plant Sci 79:343-350

Dey B (1982) Nature and possible causes of droughts on the Canadian Prairies, case studies. J Climatol 2:233-249

Dracup JA, Lee KS, Paulson EG Jr (1980) On the statistical characteristics of drought events. Water Res 16(2): 289-296

Gibbs WJ, Maher JV (1967) Rainfall deciles as drought indicators. Bulletin No. 48, Australia Bureau of Meteorology, Melbourne

Keyantash J, Dracup JA (2002) The quantification of drought: an evaluation of drought indices. Bull Am Meteorol Soc 83(8):1167-1180

Jones KH (1984) An evaluation of the Palmer Drought Index in southern Saskatchewan. Report No. CSS-R84-01, Atmospheric Environment Service, Regina

Lang TA, Jones K (1988) A comparison of the meteorological conditions during the droughts of the 1930s and the 1980s for the Prairie provinces. Report \# CSS-R89-01, Canadian Climate Program, Regina

Longley RW (1972) The climate of the Prairie provinces. Climatological Series No. 13, Environment Service, Department of the Environment, Ottawa

Mekis É, Hogg W (1999) Rehabilitation and analysis of Canadian daily precipitation time series. Atmos Ocean 37(1): $53-85$

Nemanishen W (1998) Drought in the Palliser Triangle. Agriculture and Agri-Food Canada, Prairie Adaptation Research Collaborative, Regina

Nyirfa WN, Harron WR (2001) Assessment of climate change on the agricultural resources of the Canadian prairies. 
Agriculture and Agri-Food Canada, Prairie Farm Rehabilitation Administration, Regina

Palmer WC (1968) Keeping track of crop moisture conditions nationwide: the new crop moisture index. Weatherwise 21:156-161

Phillips D (1990) The climates of Canada. Environment Canada, Toronto

Quiring SM (2004) Growing-season moisture variability in the eastern USA during the last 800 years. Clim Res 27(1):9-17

Quiring SM, Papakryiakou TN (2003) An evaluation of the agricultural drought indices for the Canadian prairies. Agric For Meteorol 118(1):49-62

Raddatz RL, Ash GH, Shaykeywich CF, Roberge KA, Graham JL (1996) First and second-generation agrometeorological models for the Prairies and simulated water-demand for potatoes. Can J Soil Sci 76(3): 297-305

Sauchyn DJ, Skinner WR (2001) A proxy record of drought severity for the southwestern Canadian plains. Can Water Res 26(2):253-255

Shabbar A, Khandekar ML (1996) The impact of El Niño/

Editorial responsibility: Otto Kinne,

Oldendorf/Luhe, Germany
Southern Oscillation on the temperature field over Canada. Atmos Ocean 34(2):401-416

Shepherd A, McGinn SM (2003) Assessment of climate change on the Canadian prairies from downscaled GCM data. Atmos Ocean 41(4):301-316

Statistics Canada (2002) Farm data for the 2001 Census of Agriculture. Statistics Canada, Ottawa

Street RB, Findlay BF (1981) An objective climatological study of prolonged dry spells (meteorological drought) in the Canadian Prairies. Report No. 81-10, Canadian Climate Centre, Atmospheric Environment Service, Downsview

Svoboda M, LeComte D, Hayes M, Heim R and 8 others (2002) The Drought Monitor. Bull Am Meteorol Soc 83(8): 1181-1190

Tilman D, El Haddi A (1992) Drought and biodiversity in grasslands. Oecologia 89(2):257-264

Wheaton EE (1998) But it's a dry cold: weathering the Canadian Prairies. Fifth House, Calgary

Wittrock V, Ripley EA (1999) The predictability of autumn soil moisture levels on the Canadian Prairies. J Climatol 19(3): 271-289

Submitted: September 7, 2004; Accepted: February 27, 2006 Proofs received from author(s): March 13, 2006 